\title{
O PACIENTE ESCREVE SUA HISTÓRIA: PRODUÇÕES TEXTUAIS DOS PACIENTES DO MANICÔMIO JUDICIÁRIO DE SÃO PAULO \\ (1910-1923)
}

\section{THE PATIENT WRITES HIS HISTORY: TEXTUAL PRO- DUCTIONS OF PATIENTS IN JUDICIAL ASYLUM OF SÃO PAULO (1910- 1923)}

Bianca Jaqueline de Moraes Vicente Gabriela Moreira de Almeida

Gabrielle Ramos da Silva Guilherme Fernandes de Moura

Resumo: Este artigo é resultado de uma parceria entre o grupo PETHistória UNIFESP (Universidade Federal de São Paulo) e o APESP (Arquivo Público do Estado de São Paulo), que é responsável pela salvaguarda do acervo do qual se vai tratar aqui. $\mathrm{O}$ artigo teve seu desenvolvimento entre os anos de 2013 a 2015 e a partir de produções textuais dos internos do Manicômio Judiciário de São Paulo, datadas de 1910 a 1923. O artigo busca analisar a perspectiva do interno diante da instituição e da sua condição. Em outras palavras, examinar quais eram e como se manifestavam suas concepções acerca dos diagnósticos e da doença; percepções sobre o funcionamento da própria instituição e sobre sua existência dentro dela. Assim, pretende-se dar voz ao interno que estava submetido àquele ambiente e refletir sobre a instituição enquanto lugar de exercício de poder. Portanto, escritos dos internos permitem questionar a pretensa passividade, cujo protagonismo pretendemos ressaltar.

Palavras-chave: Produções textuais; Prontuários; Manicômio Judiciário. 
Abstract: This article is the result of a partnership between PETHistory Unifesp group (Federal University of São Paulo) and the State of São Paulo Public Archive, responsible for safeguarding the collections which will be discussed here. The article had its development between the years 2013-2015 and from textual productions of the Judicial Asylum of São Paulo internal, dated between 1910-1923. This article search for analyze the perspective of the internal against of the institution and its condition. In other words, examine what they were and how to manifest their views about the diagnosis and disease; perceptions about own institution and of your existence within it. Thus, we intend to give voice to the internal, which was subject to that environment, and think of the institution as a place of exercising power. Therefore, these writings of internals allow us to question the alleged passivity, whose role we seek to emphasize.

Keywords: Textual Productions, Medical Records, Judicial Asylum.

\section{Introdução}

Este artigo surgiu de um projeto envolvendo os estudantes vinculados ao Programa de Educação Tutorial (PET) História da Universidade Federal de São Paulo. Em parceria com o Arquivo Público do Estado de São Paulo, que custodia o acervo de prontuários do Manicômio Judiciário do Estado de São Paulo, sistematizamos dados desses documentos em uma planilha, a fim de construir uma ferramenta de pesquisa.

A instituição teve sua origem no Hospício Central do Juquery, inaugurado em 1897, no município de Juquery (atualmente denominado Franco da Rocha). Em 1927, parte do complexo passou a abrigar o Manicômio Judiciário do Estado de São Paulo, designado para o tratamento e custódia de criminosos diagnosticados com alguma doença mental. Em 1988, o Manicômio passou a ser chamado de Hospital de Custódia e, hoje, o órgão está ligado à Secretaria de Administração Penitenciária, 
oficialmente, nomeado por Hospital de Custódia e Tratamento Psiquiátrico Professor André Teixeira Lima ${ }^{1}$.

Na virada do século XX para o XXI, um incêndio no Hospício do Juquery destruiu parte dos prontuários existentes em seu arquivo. Dos que restaram, 2.252, foram transferidos para o Arquivo Público do Estado de São Paulo, com datas limites entre 1897 e 1952, considerando a data de internação do paciente. Devido à vasta quantidade da documentação, foi estipulado pelo grupo um recorte temporal de 1899 até 1930, para finalização da coleta de dados, com o objetivo de buscar temas a serem trabalhados a partir da documentação.

$\mathrm{O}$ presente artigo visa investigar a perspectiva do paciente do Manicômio Judiciário a partir dos dados da planilha e da análise das fontes. Para isso, serão privilegiados os documentos textuais escritos pelos próprios pacientes, ou seja, as poesias e cartas anexadas aos prontuários e que nunca chegaram aos seus destinatários. Encontramos esse tipo de fontes no recorte temporal de 1910 a 1923.

A criação de um hospital onde se pudesse estabelecer um tratamento específico da loucura ocorreu durante o Brasil oitocentista, momento em que os métodos e procedimentos para lidar com a questão buscavam inspiração na Psiquiatria francesa. Era o momento em que se estabelecia a conquista de um espaço próprio para o tratamento psiquiátrico, que foi, durante muitos anos, deixado de lado pela Medicina, surgindo dali o reconhecimento da loucura como doença para a qual deve-

${ }^{1}$ Sobre a história do Juquery, ver CUNHA, Maria Clementina Pereira. O espelho do mundo: Juquery, a história de um hospício. Rio de Janeiro: Paz e Terra, 1989. 
ria haver tratamento específico. Além disso, o tratamento psiquiátrico foi também uma conquista simbólica, em que se estabelecia uma relação de poder do médico em relação ao paciente (Oliveira, 2013).

Antes mesmo de existir uma psiquiátrica científica, era adotada a assistência mental através do isolamento - já que, de acordo com a Psiquiatria francesa, a grande causa da loucura do indivíduo estaria em suas relações, familiares ou não (Oliveira, 2013). Assim, o surgimento do hospício significou a existência de um local próprio e com infraestrutura para tratar a doença, onde se daria a ruptura entre o indivíduo e suas relações cotidianas.

Isolando determinados grupos de indivíduos, a Psiquiatria no Brasil seguiu moldando comportamentos e estabelecendo padrões. Aos poucos, o hospício deixava de ser apenas uma instituição assistencial, adotando então o pressuposto de atender interesses regionais, individuais e das elites de moldar uma sociedade ideal, com padrões determinados a partir de um modelo higienista: os que se encontravam fora deste modelo não estariam aptos para viver em sociedade (Oliveira, 2013). A instituição tornou-se, um lugar para descartar os que não se encaixavam nos padrões sociais, um ambiente de limpeza e reabilitação do indivíduo, isolando os males sociais.

Os hospícios consolidam-se inicialmente como espaços destinados à cura, à regeneração e às tarefas de "assistir, tratar e consolar" um tipo especial de enfermos da razão incompatibilizados com as disciplinas requeridas pela ordem burguesa. Constitui, em outras palavras, um espaço médico 
destinado a indivíduos que já não cabiam na ordem social, sob o comando de "especialistas" de uma modalidade médica que não então se inaugurava. (Cunha, 1989).

Os prontuários da instituição são fontes importantes para entender diversos aspectos do tratamento psiquiátrico entre os séculos XIX e XX no Brasil e da sociedade da época. O prontuário é o documento por meio do qual os médicos acompanham o tratamento do paciente. Nele, são fichados dados importantes sobre os pacientes, tais como o nome, nome dos pais, gênero, cor, condição (geralmente réu, por se tratar de um manicômio judiciário), diagnóstico, profissão e nacionalidade, entre outros. Através deles sabemos também a quais exames os pacientes foram submetidos, que remédios foram prescritos, qual o tratamento aplicado, como o paciente reagiu e qual o comportamento deste, na visão do médico.

No prontuário, existe ainda um espaço destinado à anexação de cartas, o "serviço social". Ali, encontramos principalmente cartas de familiares, que não são o objeto deste trabalho ${ }^{2}$. As produções textuais analisadas neste trabalho estão presentes no em outras seções dos prontuários e, portanto, não eram tratadas como "serviço social", mas como pertencente ao prontuário em si, ou seja, eram importantes para atestar a condição de saúde mental do paciente.

\footnotetext{
${ }^{2}$ Ver BARBOSA, Vinícius; FOGAÇA, Thaís Aparecida; LIMA, Larissa Alves de; PAFFILE, Vitor. "Na expectativa de breve resposta": uma análise da comunicação epistolar entre o Manicômio Judiciário de São Paulo e a família do interno (no prelo).
} 


\section{O paciente e a instituição}

Instituições como os manicômios, são consideradas lugares onde estão representadas as formas de exercício do poder sobre os indivíduos e sobre a sociedade, tema abordado por Michel Foucault (2002). ${ }^{3}$ Tipos sociais são selecionados direta ou indiretamente para pertencerem a cada gênero de instituição, a qual desenvolve mecanismos para classificar e moldar os comportamentos individuais, de acordo com os preceitos do saber médico psiquiátrico.

Para além das instituições e dos saberes científicos, este texto busca transpor as grades dessa "instituição total" (Goffman, 1974) e dos discursos em torno dela. Nessa busca, a vida dos pacientes e as histórias desses sujeitos são o foco central do texto. Embora o prontuário seja um documento produzido pela instituição e para o seu uso, não buscaremos uma análise do Manicômio por ele mesmo, ou seja, pela documentação e discursos produzidos pela administração institucional ou por médicos. No prontuário, buscamos as palavras dos próprios pacientes em relação às vivências no lugar onde se encontravam, ao diagnóstico que receberam e aos médicos com quem lidavam.

Não analisar o Manicômio por meio da sua própria leitura e definição é o desafio deste trabalho. Sabemos, no entanto, que as cartas foram inseridas nos prontuários da própria instituição e, portanto, passaram por uma seleção. Médicos anexaram tais escritos aos prontuários com o propósito de atestar a loucura do paciente ou de impedir que ele

\footnotetext{
${ }^{3}$ Há também um conjunto de obras de Foucault pautadas neste conhecimento, entre elas História da loucura na idade clássica, $5^{\mathrm{a}}$ ed., São Paulo: Perspectiva, 1997 e O poder psiquiátrico, São Paulo: Martins Fontes, 2006.
} 
transmitisse informações a respeito de seu tratamento para a família (Cunha, 1989).

Também não se pode deixar de levar em consideração que os pacientes escreviam de dentro do Manicômio e, portanto, influenciados diretamente pelo que acontecia na instituição. A compreensão da existência dos escritos anexados aos prontuários é parte da análise pretendida neste trabalho, em que tentamos verificar em que medida a vivência na instituição influenciava o comportamento dos pacientes.

Essa visão está presente na historiografia sobre a loucura e a Psiquiatria, que consiste em dar voz aos pacientes de instituições manicomiais. Uma referência desse tipo de análise está presente nos trabalhos da historiadora Yonissa Marmitt Wadi. Ela observa, a partir da década de 1990, uma nova tendência, que dispensou atenção a novas formas de análise e fontes - no caso, as cartas produzidas pelos pacientes dos manicômios (Wadi, 2011). Ao levar em conta novas fontes e novas perguntas sobre o manicômio, é possível tentar enxergar a instituição pela visão dos pacientes. Os escritos que em sua maioria fornecem a base para esse tipo de análise possuem uma grande riqueza, de acordo com Wadi:

Alguns dos internos delinearam em seus escritos o processo de sua enfermidade, os tratamentos buscados (antes e depois da internação), seu encontro com as práticas e o poder médico; alguns outros se limitaram a reivindicar sua condição de não louco, condição atestada por médicos, psiquiatras (ou não) quando da internação nas instituições; outros ainda rememoram suas vidas até o momento da internação, ora no sentido de defenderem-se da acusação de serem loucos, ora acusando outrem (especialmente familiares, 
amantes, inimigos etc.) pela imputação da loucura a eles dada (WADI, 2010:331-362).

Para a análise dos escritos dos pacientes do Manicômio Judiciário de São Paulo, é preciso entender as possibilidades e limitações das fontes. Estas poderiam ser escritas por diversos motivos, como contatar a família, pedir notícias de familiares e também como modo de resistência à instituição.

Os médicos tinham o controle sobre estas produções textuais. $\mathrm{Na}$ avaliação e no diagnóstico final, consideravam o conteúdo e a forma escritos pelos pacientes. Dessa maneira, é possível encontrar alguns pacientes que exerciam a escrita em benefício próprio, cientes de quem seria, de fato, o leitor de suas cartas e que informações gostariam de passar a este, jogando assim, com a prática de vigilância por parte da instituição. Parafraseando Joan Scott, "escrever é reprodução, transmissão - a comunicação do conhecimento conseguido através da experiência" (SCOTT, 1999:3), ou seja, a escrita serviu de respaldo para transpor outros diálogos que ocorriam no manicômio e que ultrapassavam o discurso institucional. Dessa forma, a escrita possibilitava ir além do que era a imposto àqueles internos.

Para Scott, os sujeitos são construídos através da experiência. A autora demonstra, então, a imensidão de discursos sobre a maneira de ver o sujeito, não inferiorizando ou enfatizando uma maneira específica, mas sim dando abertura para a leitura e discussão. Para a historiadora, 
Eles não são indivíduos unificados, autônomos, que exercem o livre arbítrio. Mas, ao contrário, são sujeitos cujo agenciamento é criado através de situações e posições que lhes são conferidas. Ser um sujeito significa estar "sujeitado a condições de existência definidas, condições de designação de agentes e condições de exercício. (SCOTT, 1999:16).

O intuito deste artigo dialoga com a ideia da autora: dar voz ao paciente, antes ocultado pela própria instituição manicomial, sendo esta uma possibilidade de compreensão e uma amostragem dos discursos ali existentes.

Considerando as limitações da fonte, é preciso entender que as produções textuais existentes nos prontuários são uma seleção cujos critérios desconhecemos. Não sabemos se tudo o que foi escrito acabou anexado aos prontuários. Alguns textos podem ter sido enviados, outros descartados. Na leitura, enfrentamos a falta de entendimento do contexto de produção da fonte para além de terem sido escritas na instituição psiquiátrica e se referirem a um sujeito de quem só podemos nos aproximar por meio dos documentos produzidos sobre ele, mas quase nunca por ele, e sempre à revelia dele.

Optamos, assim, por uma análise que atentará para os silêncios do documento. Tal silêncio não se limita à ausência de explicações no prontuário; temos que lidar também com um silêncio que não descobrimos por interpretação ou por imaginação histórica. Há dados que a fonte não é capaz de dizer - por exemplo, qual era a eficácia da repressão institucional ao longo do período recortado. 
Em sua maioria, as cartas encontradas nos prontuários são destinadas à família do paciente ou aos próprios funcionários da instituição. O conteúdo destas são, geralmente, sentimentos e pedidos de seus remetentes:

\begin{abstract}
A partir de Bourdieu, pode-se falar que as cartas fazem parte de e expressam habitus, ou seja, comportamentos, regidos por valores próprios de uma dada época ou grupo social no qual se inserem ações individuais, num jogo entre indivíduo e contexto que constitui a dimensão da individualidade. Na individualidade, a coerência, a coesão, as ações e relações facilmente inteligíveis não podem ser buscadas como regra metodológica. O historiador poderá selecionar momentos significativos, as conexões que dão coerência à vida de uma pessoa e, assim, construir uma continuidade de atos que são descontínuos, justapostos, imprevistos e aleatórios (MALATIAN, 2009:195-221).
\end{abstract}

Durante o trabalho de organização dos prontuários realizado pelo grupo, foram encontradas seis cartas e três poemas, escritos entre os anos de 1910 e 1923. Não será feita uma análise quantitativa e serial desses escritos; prestaremos atenção ao evento singular, valorizando o indivíduo, o que se insere na mudança de perspectiva de análise ao lidar com as cartas observadas por Teresa Malatian (2009: 195).

Aqui, os escritos são o meio para entender a perspectiva dos indivíduos internados no Manicômio Judiciário acerca da instituição e da sua própria existência, uma vez que a carta constitui "a singularidade do indivíduo numa dimensão coletiva" (Malatian, 2009: 200). Uma análise complexa, levando-se em conta o tipo de fonte, o contexto e o lugar em 
que o indivíduo vivia e o contexto da época. Assim, entende-se que o trabalho do historiador aqui será de prospecção e levantamento de possibilidades, levando em consideração a dificuldade de supor uma coerência e continuidade de atitudes, sentimentos ou opiniões nas cartas, conforme afirmou Malatian.

\section{O protagonismo do paciente}

A instituição psiquiátrica buscava, por métodos variados, conter e controlar o comportamento do paciente e tratá-lo não como sujeito de sua própria história e individualidade, mas como uma peça manipulável. Aos pacientes não se colocava o direito individual de terem suas cartas enviadas, como acontece com as cartas de indivíduos "normais", não institucionalizados.

No contexto manicomial, uma produção textual do interno possui outros significados e usos distintos das cartas de indivíduos não internados. Ela pode potencialmente tornar-se uma peça do prontuário médico do seu autor e ser usada para atestar algum tipo de comportamento desviante (Wadi, 2005). No entanto, o poder do manicômio não é total sobre o indivíduo, pois ele consegue ser lido pelo menos pelo médico ou enfermeiro, sujeitos que raramente lhes dão voz.

J. C. N. ${ }^{4}$ escreveu uma carta com a intenção de ser lido por alguém no Manicômio Judiciário. Sua carta foi endereçada para o "Exce-

\footnotetext{
${ }^{4}$ Sempre serão usadas apenas as iniciais do nome do paciente, para manter em sigilo sua identidade e, eventualmente, as de seus familiares.
} 
lentíssimo Senhor Dr. Franco da Rocha"5. Na primeira página do prontuário, J. C. N. dizia ter 26 anos à data de sua internação, em 7 de dezembro de 1912. Branco, funcionário público, casado, católico, brasileiro, nascido no interior de São Paulo, ele entrou no Manicômio na condição de réu acusado de homicídio. Foi diagnosticado com sífilis e "demência precoce" e, na documentação, não consta a data de sua saída. É provável que tenha deixado a instituição por óbito, como inúmeros prontuários deixam claro.

Em uma carta escrita em 31 de dezembro de 1912, pouco depois de dar entrada no Manicômio, o interno reconhece seu crime como um erro e apresenta seus motivos para sair da internação/prisão. Um sujeito que passou por intenso processo de desindividualização busca meios para resistir às tantas barreiras que lhe eram impostas. Reconhecer o crime e considerá-lo em erro poderia ser uma forma de usar os mesmos padrões vigentes no Manicômio, buscando motivos para sua cura, e, consequentemente, para sair da instituição.

Não faz sentido para o historiador investigar se, de fato, o paciente internado sofria de alguma doença mental. De todo modo, ele demonstrava ter consciência de sua condição e afirmava querer agir diante dela: “(...) acho-me agora de boa saúde e capaz de guiar-me por mim próprio" $"$.

\footnotetext{
${ }^{5}$ Francisco Franco da Rocha fora médico psicanalista, e um dos percursores no tratamento de doenças mentais no país. Em 1896 fundou o Hospício de Juquery aonde se aposentou como diretor no ano de 1923.

${ }^{6}$ Arquivo Público do Estado de São Paulo, Manicômio Judiciário do Estado de São Paulo, caixa 5, prontuário DAP 239.
} 
A julgar pela visão dos pacientes, o Manicômio é um lugar onde eles não gostam de estar, já que, nas cartas, o pedido é sempre para sair dali. Na mesma carta citada, o paciente diz querer ir embora para tratar dos seus negócios. O argumento era importante na ordem social "normal", pois o trabalho era considerado um valor moral desejável e o paciente, nesse caso, usou tal argumento a seu favor, lidando com os valores e ideais projetados pela instituição. A fim de tratar da saúde do paciente, eram usados métodos como a laborterapia ${ }^{7}$ e outras orientações morais, de forma que a instituição tentava se apoderar não só da condição biológica do paciente, mas também da sua individualidade e consciência.

Em outra carta do mesmo paciente, escrita em 13 de outubro de 1913 e dirigida ao "Exelentisimo Senhor Doutor", ele diz ser "perseguido pelas correntes Magnéticas" e relata “a V. $E^{\mathrm{xa}}$. o estado em que me acho e ao mesmo tempo pesso a $\mathrm{V}$. $\mathrm{E}^{\mathrm{xa}}$. o favor acima dito: [...] peço que mande-me para qualquer dependencia deste Hospicio pois assim as correntes me esquecem". Ele especifica que deseja ir "para as fazendas ou para uma das colônias". Na carta, ele informa ainda que tem uma família que muito o estima.

Podemos verificar que o paciente tinha noção de sua condição, porque sabia em que lugar do manicômio estava e para onde queria ser transferido. Ele destina sua carta diretamente ao médico, mostrando

${ }^{7} \mathrm{O}$ "tratamento moral" foi proposto por Philippe Pinel na França do século XVIII. A laborterapia era um desses tratamentos, que impunha trabalhos aos pacientes na agricultura e na pecuária como forma de atestar a sua normalidade ou não. Ver: TARALOW, Gustavo Querodia. Entre comas, febres e convulsões: os tratamentos de choque no Hospital do Juquery (1923-1937). São Paulo: UFABC, 2013 
saber a que cargos ele estava submetido e conhecer sua condição de paciente. Dessa forma, J. C. N. tentava interferir no tratamento, no tempo de internação e no funcionamento da instituição por meio das cartas. A princípio queria sair, depois desejou ser transferido; refletia, portanto, sobre sua condição dentro do Manicômio, pretendendo melhorá-la.

Além de um ser lugar difícil para se viver, podemos supor outra ideia sobre o Manicômio, expressa por Marmitt Wadi ao narrar o caso de Ulysses, que encontrou na instituição um espaço tranquilo para se expressar por meio da escrita (Wadi, 2011). De modo similar, F. encontrou no Manicômio um lugar em que era possível escrever. F. tinha 72 anos ao ser internado: era italiano, branco, viúvo e procedente de Santa Rita de Passa Quatro.

Não sabemos se para F. escrever foi uma atividade fácil de realizar no Manicômio. Entre sua entrada (em junho de 1923) e a data de seu falecimento (agosto de 1926), ele escreveu três poemas de cunho romântico, em que diz como ele se sentia. Assim, percebemos que ele existia enquanto indivíduo e não só como um paciente passivo e submetido às condições impostas pelos doutores do Manicômio.

F. escreveu três poemas: um intitulado "Beijos", que trata, de forma romantizada, de um beijo; outro chamado " $O$ gondoleiro do amor", também de teor sentimental, exaltando o amor relacionando aos elementos da natureza e com menção à Itália, sua terra natal; por fim, "O Ignoto", em que o autor se dirige a uma donzela e diz que não pode contar quem ele é porque é uma pessoa "já cansada de tanto sofrer”: 
“[...] Quem sou eu, não perguntes, donzella Quem eu sou, não indagues por Deus; Sou um pobre isolado no mundo, Quase a morte distante dos meus! [...]" (APESP/MJ, caixa 18, prontuário DAP 154.)

Podemos ver nesses poemas que o autor tinha certa sensibilidade para o romance. Além disso, podemos cogitar que a dor e a melancolia expressas em "O Ignoto" se referem à sua própria existência dentro Manicômio. Além dos poemas, o mesmo paciente escreveu duas cartas que foram anexadas ao seu prontuário. Em uma, ele se dirige a um funcionário da instituição, de cargo não informado, pedindo, em tom de apelo, a absolvição do crime (também não informado) a que fora condenado:

[...] Sei que fostes sorteado para servir na $2^{\text {a }}$ Sessão do Jury desta feliz Comarca e como, durante Ella, serei julgado por um crime que inconscientemente pratiquei, venho de mãos postas, não perdi-vos façais justiça, porque esta já estou certo que a vossa consciência fará, mal rogar-vos tenhais compaixão de mim, pobre velho de mais de setenta anos, asthmatico e alquebrado, à mercê de um destino que me tem sido cruel[...]" (APESP/MJ, caixa 18, prontuário DAP 154.)

Dizendo acreditar na bondade do coração do destinatário, lembrao de que Deus o recompensará pelas suas boas ações:

“[...] Deus, que não esquece as boas acções, La de vos recompensar, cobrindo-vos, e a vossa distenctissima família, com as suas santas bençans, já que não vos posso pagar sendo com o meu profundo, sincero e eterno reconhecimento[...]" (APESP/MJ, caixa 18, prontuário DAP 154.) 
F. pede compaixão, exprimindo consciência sobre sua condição e sobre os processos pelos quais deveria passar dentro da instituição. Tenta agir diante disso, selecionando o que dizer e a quem se dirigir. A tentativa de influenciar um membro do júri a respeito de sua pena expressa o conhecimento que o paciente tinha sobre o funcionamento do processo judicial. O paciente, através de suas produções textuais, passa a tentar construir sua própria história dentro da instituição, visto que, estando integrado a esta como interno, era moldado diante dos preceitos médi$\cos$.

Baseados Scott, podemos pensar que a atitude de F. estava de acordo com a experiência que ele possuía, e que o levava a agir diante das situações que lhes eram postas na tentativa de modificar seu estado, já que ele não parecia concordar com o que lhe impunham.

Em outra carta, que não sabemos se fora destinada à mesma pessoa, ele se mostra novamente homem crente e temente a Deus e ressalta a importância da caridade divina:

“[...] E toda creatura que sabe soccorreros infeliz preso terá uma recompensa eterna, Deus vo pague, sendo esse voto ouvido por Deus, este abre as porta do Cés[...]"(APESP/MJ, caixa 18, prontuário DAP 154.

Em outro prontuário, temos informações sobre F. H. $\mathrm{N}^{8}$, homem de 40 anos de idade, internado em 18 de dezembro de 1910 e falecido em 28 de janeiro de 1913. O paciente se negou a assinar o nome no lu-

${ }^{8} \mathrm{APESP} / \mathrm{MJ}$, caixa 3, prontuário DAP178, paciente F. H. N, fl. 10. 
gar destinado o "autographo", alegando não saber ler nem escrever. No entanto, no dia 21 de fevereiro de 1911, ele escreveu uma carta destinada ao médico, pedindo transferência para outra enfermaria a fim de poder se curar.

Assim, percebemos que ele sabia estar em um lugar para tratamento e, mais do que isso, ao escrever a carta, ele agiu ativamente diante da instituição, quando tentou intervir no seu tratamento supondo qual seria a melhor enfermaria para sua cura. A carta foi anexada ao seu prontuário para mostrar a mentira que o paciente havia contado, pois, afinal ele sabia escrever, ou seja, o documento tornou-se um indício da sua loucura.

A carta tornou-se uma peça para a investigação médica, que talvez não teria sido juntada ao prontuário se não fosse para comprovar a mentira. Destacamos a subjetivação e o poder ao qual o paciente foi submetido, já que aparentemente o pedido da carta sequer foi considerado.

\section{Considerações finais}

As descrições do Manicômio Judiciário de São Paulo através das produções textuais dos pacientes no intervalo aqui recortado possibilitam diversas análises sobre a vivência do paciente dentro da instituição e sobre os limites do saber e do poder desta, além de propiciar uma reflexão histórica sobre os limites da própria Psiquiatria.

A instituição se fez presente, de modo incisivo, no controle dos pacientes, pressupondo o poder sobre seus corpos, seus pensamentos e 
sua individualidade, ao mesmo tempo em que subestimava a construção ativa de sua própria história por parte dos pacientes. No entanto, alguns deles buscaram transpor os muros da instituição e encontraram meios de exprimir suas ideias.

No caso de F. H. N., por exemplo, sua intervenção pode não ter sido eficaz, mas foi ativa. A instituição, por fim, suprimiu o desejo do paciente e tentou silenciá-lo ao apenas anexar a carta ao prontuário, sem discuti-la. Mas ele foi capaz de escrever e sua escrita demonstra que ele não era passivo, mas protagonista da sua história, da qual restou um pequeno registro que nos deixa ao menos entrever algo de sua experiência.

A historiografia sobre a loucura e a Psiquiatria é relativamente recente. Devido às diversas possibilidades de interpretação e ao reduzido número de produções textuais encontradas em nosso recorte, torna-se difícil encontrar respostas para a questão proposta neste artigo. Mas, no recorte adotado aqui, podemos afirmar que as cartas e outros registros textuais produzidos pelos pacientes são importantes para se estudar o cotidiano e as histórias destes para além do discurso médico e institucional.

A carta encontrada no prontuário, muitas vezes é a única manifestação do paciente que encontramos. Escrever uma carta é uma "escrita de si, na primeira pessoa, na qual o indivíduo assume uma posição reflexiva em relação à sua história e ao mundo onde se movimenta" (Malatian, 2009: 195). Alguns escritos podem ter sido produzidos a pedido da instituição, outros de espontânea vontade fazendo pedidos aos funci- 
onários do Manicômio ou a suas famílias. De qualquer forma, o paciente escreve sobre si em um momento de introspecção e constrói a imagem sobre si que deseja externar (Malatian. 2009: 197).

A análise de fontes escritas aponta novas possibilidades historiográficas no estudo do tema. Os prontuários do Manicômio Judiciário de São Paulo nos proporcionam uma vasta documentação para pesquisas que buscam outra perspectiva que não seja a da própria instituição e a de seus dirigentes e corpo médico como únicos protagonistas da história.

Aos olhos da instituição o controle sobre os pacientes era efetivo, já que esta conseguia suprimir a subjetividade do indivíduo ignorando informações como as contidas nas cartas. No entanto, a análise das produções dos pacientes nos mostra que a instituição não tinha total controle sobre o pensamento e a subjetividade do indivíduo: ele continuava refletindo sobre si, agindo ativamente em sua própria história.

\section{Bibliografia}

CUNHA, Maria C. P. O espelho do mundo: Juquery, a história de um asilo. Rio de Janeiro: Paz e terra. 1989

FOUCAULT, Michel. Vigiar e Punir. Petrópolis: Vozes, ed.25, 2002.

GOFFMAN, Erving. Manicômios, prisões e conventos. São Paulo: Perspectiva, 1974.

MALATIAN, Teresa. Narrador, registro e arquivo. IN: O historiador e suas fontes. PINSKY, Carla Bassanezi; LUCA, Tania Regina de. Org. São Paulo: Editora Contexto, 2009. p-195-221.

OLIVEIRA, William Vaz de Oliveira. Discursos e práticas psiquiátricas no Brasil oitocentista: O hospício de Pedro II e o processo de medicali- 
zação da loucura. III Simpósio de História do Maranhão oitocentista. Impressos no Brasil do século XIX, Maranhão, 2013.

SCOTT, Joan. Experiência. Falas de Gênero. Organização de Alcione Leite da Silva, Mara Coelho de Souza Lago e Tânia Regina Oliveira Ramos. Editora Mulheres, Santa Catarina, 1999. Pp. 21-55

TARELOW, Gustavo Querodia. Entre comas, febres e convulsões: os tratamentos de choque no Hospital do Juquery (1923-1937),

WADI, Yonissa Marmitt. A escrita epistolar no hospício: documento médico, documento histórico. In: Revista Latinoamericana de Psicopatologia Fundamental, vol. VIII, núm. 1. São Paulo: 2005.

WADI, Yonissa Marmitt. Entre muros: os loucos contam o hospício. Topoi v.12,n.22, jan-jun- 2011, p. 252-253.

WADI, Yonissa Marmitt. "Um lugar (im)possível: narrativas sobre o viver em espaços de internamento". In: WADI, Yonissa Marmitt e SANTOS, Nádia Maria Weber (orgs.). e loucura: saberes, práticas e narrativas - Uberlândia: EDUFU, 2010. p-331-362.

WADI, Yonissa Marmitt. "Uma história da loucura no tempo presente: os caminhos da assistência e da reforma psiquiátrica no Estado do Paraná”. In: Tempo e Argumento: - Revista do Programa de Pós-Graduação em História. Santa Catarina: 2009

Recebido em: 29/10/2016 Aceito em: 16/12/2016 